\title{
Optimization of Headspace Solid-Phase Microextraction Conditions for the Identification of Volatiles Compounds from the Whole Fruit of Lemon, Lime, Mandarin and Orange
}

\author{
Khalid Mohammed1,2, Manjree Agarwal1, James Newman1, Yonglin Ren ${ }^{*}$ \\ ${ }^{1}$ School of Veterinary and Life Science, Murdoch University, Murdoch, Australia \\ ${ }^{2}$ College of Agriculture and Forestry, University of Mosul, Mosul, Iraq \\ Email: *y.ren@murdoch.edu.au
}

How to cite this paper: Mohammed, K., Agarwal, M., Newman, J. and Ren, Y.L. (2017) Optimization of Headspace SolidPhase Microextraction Conditions for the Identification of Volatiles Compounds from the Whole Fruit of Lemon, Lime, Mandarin and Orange. Journal of Biosciences and Medicines, 5, 176-186. https://doi.org/10.4236/jbm.2017.53019

Received: March 16, 2017 Accepted: March 31, 2017 Published: April 3, 2017

\begin{abstract}
An optimum method has been developed for extracting volatile organic compounds (VOCs) which contribute to the aroma of different species of citrus fruit (orange, lemon, lime, and mandarin). Headspace solid phase microextraction (HS-SPME) combined with gas chromatography (GC) coupled with flame ionization detection (FID) is used as a very simple, efficient and nondestructive extraction method. A three phase 50/30 $\mu \mathrm{m}$ PDV/DVB/CAR fibre was used for the extraction process. The optimal sealing time for volatiles reaching equilibrium from whole fruit in the headspace of the chamber was 20,16, 8 and 16 hours for lemon, lime, mandarin, and orange respectively. Optimum fibre exposure times for whole fruit were 2, 4, 2 and 2 hours for lemon, lime, mandarin, and orange respectively. Three chamber volumes $(500,1000$ and $2000 \mathrm{ml})$ were evaluated for the collection of VOCs with the $500 \mathrm{ml}$ chamber being selected. The $500 \mathrm{ml}$ chamber produced the highest quality peak areas and quantity of extracted volatiles. As a result of fruit respiration, the percentage of oxygen $\left(\mathrm{O}_{2}\right)$ of all citrus fruit species in $500 \mathrm{ml}$ chamber decreased from $21.8 \%$ to $18.8 \%$ in the 20 hours sealing time, while carbon dioxide $\left(\mathrm{CO}_{2}\right)$ contents increased to $2.9 \%$ also in the 20 hours sealing time. The results of this study showed the feasibility of this technique for identifying VOCs from four of the citrus fruit species and its potential as a routine method for physiological studies on citrus fruit or on other fruit species.
\end{abstract}

\section{Keywords}

Citrus Fruits, VOCs, HS-SPME/GC-FID, Lemon, Lime, Mandarin, Orange 


\section{Introduction}

Citrus is a genus of flowering trees and shrubs in the family of Rutaceae and is considered among the most important horticultural industries in the world. Citrus fruit have the highest international trade value of all food [1]. The contribution of the citrus industry to the world economy is estimated at more than $\$ 10$ billion USD annually [2]. The Australian citrus industry considers as one of the largest fresh fruit industries in Australia, and definitely the largest fresh fruit exporter with an annual average export volume of 170,000 tons and a value of $\$ 190$ million AUD [3]. Citrus fruit are used not only for foods and drinks but also in perfumes, cosmetic, soaps, and many other aromatic products. They are widely grown in the world's tropical and subtropical regions and are native to parts of China, India, New Caledonia and northern Australia [4]. Taxonomic identification is confounding because there are many, but citrus can generally be classified into the following categories: sweet oranges $(C$. sinensis), mandarins (C. unshi), tangerines (C. tangerina, and reticulata), and (C. clementine)), sour/ bitter oranges $(C$. aurantium), lemons ( $C$. lemon), limes ( $C$. aurantifolia and latifolia), grapefruit (C. paradisi) and pummelos (C. grandis), hybrids (e.g., tangelos, tangors, and limequats), and citrons ( $C$. medica, which have a rind that is used primarily for confectionary and is only commercially grown in limited areas). All of which are exported to various markets around the world [5].

Citrus species produce essential oils in their fruits which are used in soap, food, perfumes, repellents and others [6]. Citrus consumption depends closely on their aroma and flavour. Chemically, the aroma and flavour are given by the presence of volatile compounds that impress the olfactory receptors. Detailed analysis of the aroma components of citrus fruits is important for citrus industries to ensure the production of quality foods and free of pests and pathogens. Citrus have been considered as emitters of volatile organic compounds (VOCs) in chamber studies under controlled environmental conditions [7]. These VOCs can be extracted by various techniques, such as microwave-assisted hydrodistillation extraction, solvents and recently, solid phase microextraction (SPME) which is used to profile and quantify these compounds. Headspacesolid phase microextraction (SPME) nowadays, is considered the method of choice for most of the volatile extraction in flavour chemistry/food [8] [9] and particularly in Citrus [10] [11]. There are many methods for obtaining citrus volatiles, such as citrus oil (essential oil) and these methods have been extensively reviewed [12] [13]. Unfortunately, the aroma of extracted oils rarely represents the delicate natural aroma of citrus, because of uncontrolled temperature during the steam distillation process [14]. Likewise, other extraction methods using ground samples and solvents also frequently fail to capture the natural aromas [15]. To identify VOCs produced by citrus or other fruit, it is necessary to develop easy to operate, repeatable, sensitive, rapid and cost-effective method. Until now, there are no studies about the use of headspace solid phase microextraction (HS-SPME) technique for the whole fruit of citrus species. The SPME method is 
excessively used for the analysis of volatile compounds. The HS-SPME technique is a new, simple, rapid, eco-friendly and solvent-free sample preparation technique for the extraction of volatile compounds [16] [17]. The HS-SPME technique gives simultaneously tens or hundreds of possible volatile compounds and also provides interesting results when gas chromatography (GC) is combined with either Flame Ionization Detector (FID) or mass spectrometric detection (MS), but it must be optimized for the volatiles being targeted [18] [19]. Many factors can affect the optimization of extraction conditions, such as the correct fibre and an appropriate chamber for capturing the VOCs, the temperature used during extraction and the extraction time from the headspace [20]. So far, there has been no systematic work on optimizing extraction conditions for whole fresh citrus fruit. Therefore, this study will determine the optimal conditions of sealing time, extraction time and chamber size for citrus fruit volatile isolation by the headspace solid phase microextraction (HS-SPME) technique with gas chromatography coupled with Flame Ionization Detector GC-FID.

\section{Materials and Methods}

\subsection{Reagents}

An n-hexane 95\% was purchased from Sigma-Aldrich Australia, catalogue number 270504-2L. Ethanol was purchased from MERK (Germany) (high-performance liquid chromatography HPLC grade), and the n-Alkane standard (C7C30) was purchased from Sigma-Aldrich Australia, catalogue number 49451-U.

\subsection{Apparatus and Equipment}

An Agilent Technologies gas chromatograph 7829A (serial number CN14272038) fitted with an HP-5MS column $(30 \mathrm{~m} \times 0.25 \mathrm{~mm}$, film thickness $0.25 \mu \mathrm{m}$, RESTEK, catalogue number 13423) non-polar, with a flame ionization detector (FID) was used. The SPME extractions were carried out in three-phase Divinylbenzene/carboxen/polydimethylsiloxane DVB/CAR/PDMS fibre, 50/30 $\mu \mathrm{m}$ (Sigma-Aldrich Australia, catalog number 57347-U), which was designed for analytes with a broad range of polarities (suitable for C2-C20 range) [21] [22] (Sigma-Aldrich Australia, catalog number 57347-U), attached to a manual SPME holder (Supelco Inc.). The fibres were conditioned as recommended by the manufacturer and the supplier specifications before analyses. A 500, 1000 and $2000 \mathrm{ml}$ Pyrex (Silverlock Packaging; JG2701 FL, JG2879 FL and JG2901 FL respectively) glass jarwith a $5 \mathrm{~mm}$ port drilled into one side, into which septa (20633 Thermogreen ${ }^{\circledR}$ LB-2 Septa, plug) was placed and was used for collection of citrus fruits VOCs. Aluminum foil $150 \mathrm{~m} \times 44 \mathrm{~cm}$ (Vital Packaging Company) was used to cover the glass jar opening and extract volatile organic compounds (VOCs) emitted from fruits. Witt OXYBABY ${ }^{\circledR} 6.0$ (WIT-Gasetechnik $\mathrm{GmbH} \& \mathrm{Co} \mathrm{KG} \mathrm{T}$, Germany)was used for monitoring head space fruit concentration of carbon dioxide, oxygen, and nitrogen from respiring fruits was by inserting the needle through jars septa. 


\subsection{Samples}

Fresh samples of orange, lemon, lime and mandarin fruits were purchased from different vendors at local shopping centres. The orange, lemon and mandarin were weighed at approximately $150 \mathrm{~g}$ and the lime at approximately $100 \mathrm{~g}$. The fruit was checked and washed well with warm water to get rid of the wax, and then conditioned at room temperature $\left(25^{\circ} \mathrm{C} \pm 1^{\circ} \mathrm{C}\right)$ for $24 \mathrm{~h}$ before the experiment was conducted.

\subsection{Gas Chromatogram Condition}

The GC_FID run time was $45 \mathrm{mins}$ the oven column temperature ranged from $50^{\circ} \mathrm{C}-250^{\circ} \mathrm{C}$, programmed at $5^{\circ} \mathrm{C} / \mathrm{min}$, with a final hold time of $5 \mathrm{~min}$. Helium (He) was used as the carrier gas at $1.1 \mathrm{~mL} / \mathrm{min}$ constant flow, and detector (FID) temperatures of $290^{\circ} \mathrm{C}$, injection port temperature $250^{\circ} \mathrm{C}$, and the GC-FID instrument was operated under the splitless mode.

\subsection{Optimization of Solid-Phase Microextraction}

For optimization of the HS-SPME, the variables chosen were sealing time, extraction time and different volumes of chambers for extraction, while the SPME fibre (DVB/CAR/PDMS), the fibre extraction temperature of $25^{\circ} \mathrm{C} \pm 1^{\circ} \mathrm{C}$, the weight of samples were kept constant. In order to optimize the sealing time, extraction times and chambers volumes all factors influencing the equilibrium between the analyses and the fibre were taken into consideration. Different sealing times, different extraction times and different extraction chambers volumes were used for the different species of fresh citrus fruit. The fibres were cleaned between each extraction by placing them into the GC injection port for $15 \mathrm{~min}$ at $250^{\circ} \mathrm{C}$ to ensure the absence of carry-over peaks and contaminants in blanks and next injections to have good repeatability between the injections. All three fibres were calibrated using standard n-alkene C7-C30 after dilution in the ration of $1 / 10 \mathrm{ml}$ in $\mathrm{n}$-hexane, and then desorbed for one hour at room temperature and this procedure was repeated twice with three replications before analysis. The results presented as the mean values.

\subsubsection{Optimization of Sealing Time}

To determine the best sealing time; the citrus fruits species individually sealed in $1000 \mathrm{ml}$ glass jars for $(2,4,8,12,16$ and $20 \mathrm{~h})$. The extraction efficiency of the six different sealing time was determined by comparing the peak area of the eight compounds from all citrus fruit species under the same extraction time, SPME fibre, desorption time, and GC conditions. The fibres were exposed to the HS of the glass jars for 2 hours. After exposure, the fibres were retrieved and injected into the heated injection port $\left(250^{\circ} \mathrm{C}\right)$ of a GC-FID and desorbed for 10 min. Each sample was replicated thrice.

\subsubsection{Optimization of Extraction Time}

Each fibre was exposed to the HS of the $1000 \mathrm{ml}$ glass jar containing individual citrus fruit for 3 different time periods (1, 2 and 4 hours). After exposure, the fi- 
bre was retrieved and injected into the heated injection port $\left(250^{\circ} \mathrm{C}\right)$ of a GC-FID and desorbed for $10 \mathrm{~min}$. Each sample was replicated thrice.

\subsubsection{Optimization of Chambers Volume}

To determine the most efficient extraction method of the VOCs emitted by citrus fruits, a comparison was made between different volumes of glass jars (500, 1000 and $2000 \mathrm{ml}$ ). The results showed that $500 \mathrm{ml}$ glass jar volume achieved higher efficiency for VOCs extraction from all citrus fruits samples, so the 500 $\mathrm{ml}$ jar was chosen because it was efficient for capturing the VOCs emitted. Individually, citrus fruits were placed into the glass jar and the opening covered with aluminum foil and incubated at $25^{\circ} \mathrm{C} \pm 1^{\circ} \mathrm{C}$ for $8 \mathrm{~h}$ sealing time and $2 \mathrm{~h}$ extraction time. Each sample was conducted in triplicate.

\subsection{Gas Composition inside the Glass Jars}

An Oxybaby gas analyzer was used for monitoring headspace composition of the respiration of the citrus fruit during the sealing time in $500 \mathrm{ml}$ glass jar. Three replicates were used to determine the gas composition.

\subsection{Data Analysis}

The GC data including retention time and peak area were collected and integrated into the chromatography software Agilent Chemstation, and then exported to Microsoft Excel for further analysis. The repeatability of replicates from the same sample was verified by checking the chromatogram pattern features such as detected peak retention times and peak areas.

\section{Results}

\section{1. $\mathrm{O}_{2}$ and $\mathrm{CO}_{2} \mathrm{Headspace}$ Concentration}

As a result of fruit respiration, the contents of $\mathrm{O}_{2}$ decreased during the first two hours in varying proportions reaching $19.7 \%$ and $20.6 \%$ in orange fruit and lime, respectively. As for the lemon and mandarin fruit, oxygen consumption rate was same as control which is $20.2 \%$ (Figure $\mathbf{1}(\mathrm{a})$ ). After 20 hours sealing time, the oxygen level dropped down to $18.8 \%$ and $20 \%$ for oranges and lime respectively. Carbon dioxide had a lower accumulation in the first 2 hours of sealing time. In 4 hours of sealing time, level $\mathrm{CO}_{2}$ build up to $0.5 \%$ in lime and $1.1 \%$ in orange (Figure 1(b)). Carbon dioxide gas production continued to build up in all citrus fruit species and reached a level of $2.9 \%, 1.8 \%, 1.7 \%$ and $1.1 \%$ at 20 hours in orange, lemon, mandarin, and lime respectively.

\subsection{Analysis of Volatiles Organic Compounds in Citrus Fruit Species with Different Sealing Time}

Total peak areas from the different samples sealed for 2, 4, 8, 12, 16 and 20 hours are compared in Figure 2. The amount of volatile compounds was significantly different between those collected at different sealing times. This result showed that 20,16, 8 and 16 hours sealing period achieved higher efficiency for VOCs 


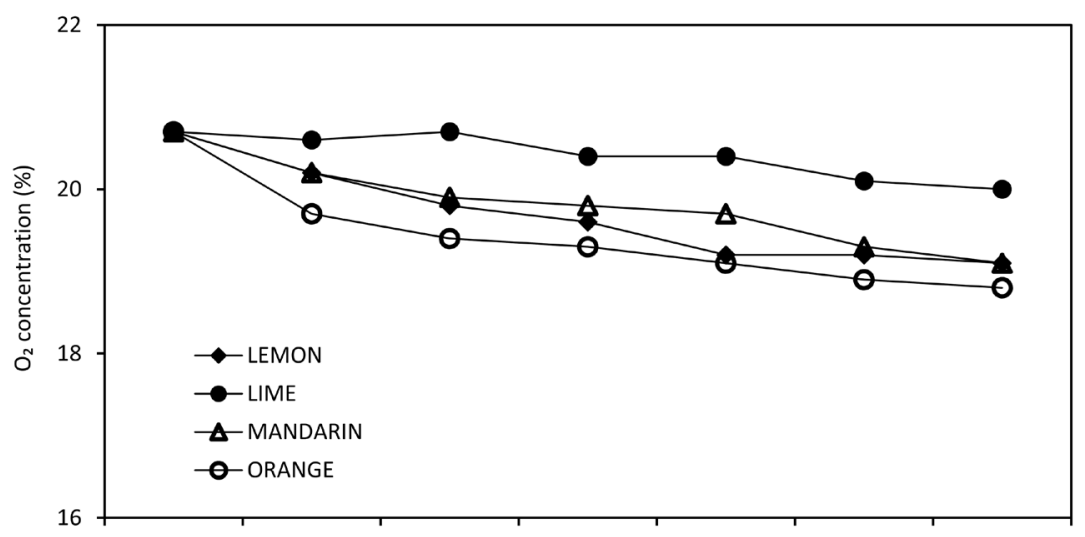

(a)

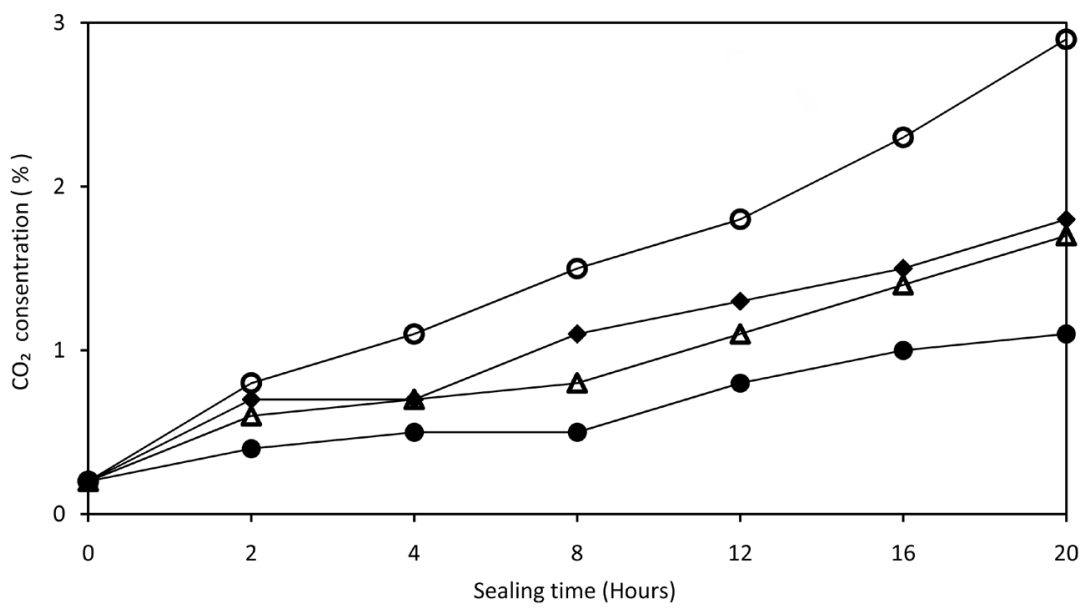

(b)

Figure 1. Effect of different sealing time on headspace gas composition $\mathrm{O}_{2}$ (a) and $\mathrm{CO}_{2}(\mathrm{~b})$ of different citrus fruits species.

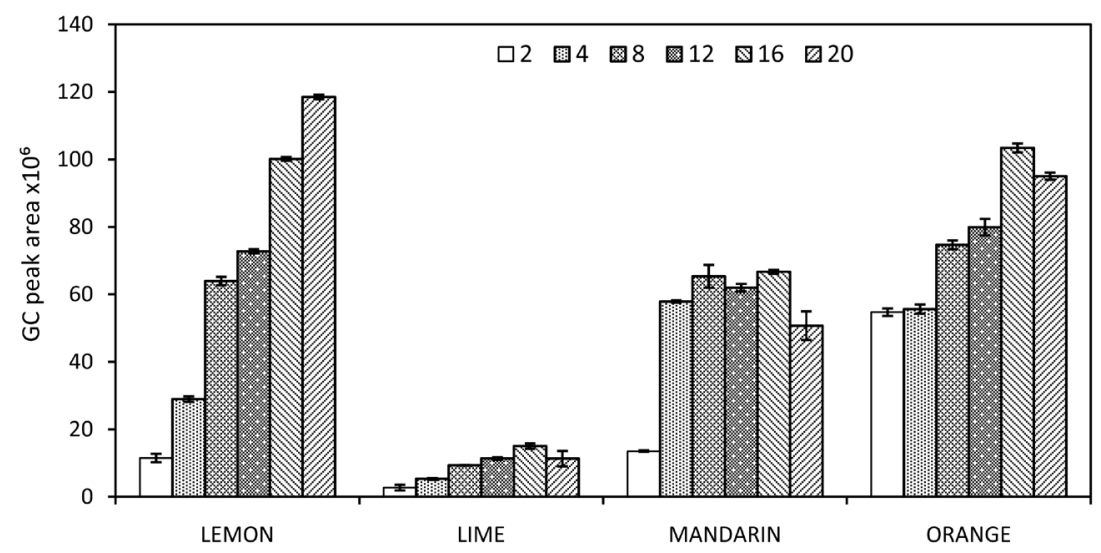

Figure 2. Peaks of volatiles organic compounds (units) produced by different citrus fruit species with 2, 4, 8, 12, 16 and 20 hours sealing time in sample preparation. Error bars are LSD at $5 \%(n=3)$.

extraction from lemon, lime, mandarin and orange samples respectively. Therefore, the 20,16, 8 and 16 hours sealing time for lemon, lime, mandarin, and orange respectively were selected for subsequent studies. 


\subsection{Analysis of Volatiles Organic Compounds in Citrus Fruit Species with Different Fibre Extraction Times}

The amount of the volatile compounds did not differ significantly between those collected at 2 and 4 hours from lemon and mandarin, while there were significant differences between them and those collected at 1 hour (Figure 3). Therefore, the 2 hours was selected for subsequent studies for both species of lemon and mandarin. In contrast, there were significant differences in the amounts of VOCs produced at the different extraction times from lime and orange fruit (Figure 3). Therefore, 2 and 4 hours were selected for best extraction time to absorb the VOCs emitted from the lime and orange respectively.

\subsection{Selection of Chamber Volume}

The extraction efficiency of the three different chambers volumes (500, 1000 and $2000 \mathrm{ml}$ glass jar) was evaluated by comparing the peak area of the eight compounds from all citrus fruit spices under the same extraction time, SPME fibre, desorption time, and GC conditions. There were significant differences between the three different chambers size, so the $500 \mathrm{ml}$ jar was chosen because it was optimum for capturing the released VOCs (Figure 4).

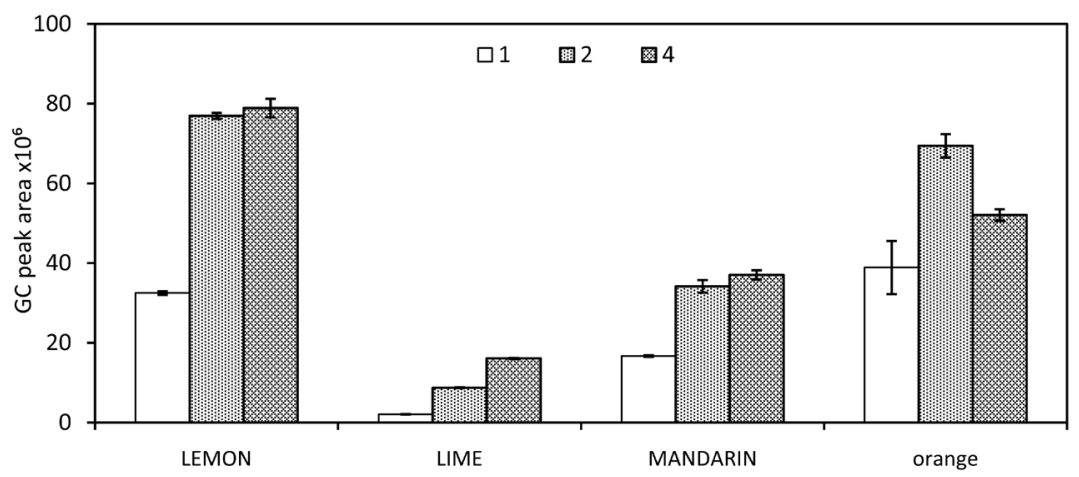

Figure 3. Effects of extraction time with citrus fruit species on the peaks area of volatiles organic compounds at 1,2 and 4 hours. Error bars were LSD at $5 \%(n=3)$.

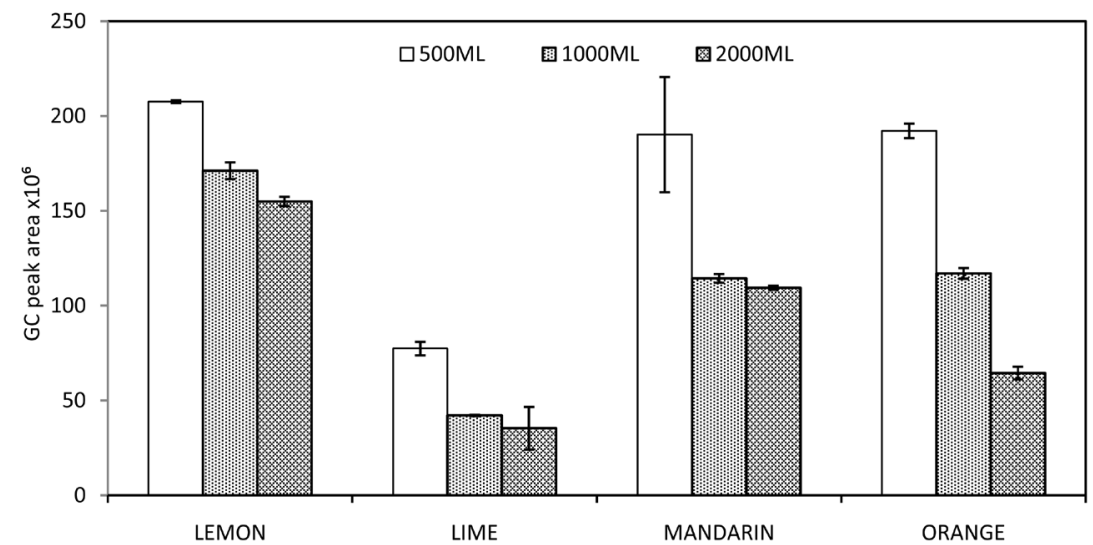

Figure 4. Peaks of volatiles organic compounds (units) produced by different citrus fruit species extracted by three sizes of chambers (500, 1000 and $2000 \mathrm{ml})$. Error bars are LSD at $5 \%(n=3)$. 


\section{Discussion}

Volatile production is an important quality characteristic of many fruits, which has been extensively studies [23] [24]. The concentration of the $\mathrm{CO}_{2}$ and $\mathrm{O}_{2}$ into glass jars is the main factor affect on the production of some volatile organic compounds related to the fruit's aroma. Our results support previous findings in the literature which showed that $\mathrm{O}_{2}$ consumption was directly related to $\mathrm{CO}_{2}$ production [25]. Extremely low $\mathrm{O}_{2}$ levels $(0.5 \mathrm{kPa})$ decreased the emission of straight-chain esters related to the aroma of 'Royal Gala' apples [26], while Barker (1928) found that carbon dioxide injury on oranges took the form of an unpleasant bitter flavour [27].

Most of our knowledge about citrus volatiles has been obtained from studies of processed juices and the peel essential oils, essence oils, and aqueous essences used to flavor juice products [10] [28]. On the contrary, optimization and extraction studies on aroma volatiles in fresh citrus fruit have not much been reported. Optimization of isolation conditions was carried out using a $1 \mathrm{~L}$ glass jar with two factors: time needed to reach equilibrium in the headspace and the fiber exposure time. Samples were analyzed by GC-FID. The criteria were a higher number of peaks and greater total area of the chromatogram. The determination of the optimum time of sealing is essential to obtain maximum efficiency of the SPME fibers for particular VOCs. The equilibrium between the citrus fruit species and its volatiles within the glass jar had an impact on the final volatile extraction by the SPME fibre. Normally if there is no significant difference between the sealing time less sealing time is prefered, which agrees with the study by [29] who isolated a number of high-quality volatiles from the headspace of whole banana using 140 min sealing time compared with 15 min for banana pulp, but in this study significant difference was observed between different sealing times so, long sealing time for fresh citrus fruits was selected to isolate high-quality volatiles.

Extraction temperature and time are significant parameters in HS-SPME since both have an effect on the equilibrium during extraction of volatile compounds [30]. In this study, optimal extraction time from the fibre for all citrus fruit species was $2 \mathrm{~h}$, except for lime reaching $4 \mathrm{~h}$ which is longer than the time used by [31] who reported $40 \mathrm{~min}$ as the optimum extraction time to extract the volatiles compounds produced by some species of citrus fruit juice. The best conditions for isolating volatiles from the headspace of whole banana fruits were $120 \mathrm{~min}$ fiber exposure, while for the banana pulp the best conditions were $60 \mathrm{~min}$ for exposure times [29]. This difference is most likely due to the different in fruit extraction part, head space volume and extraction temperature, since, the extraction time depends on the chemical nature of the compounds present, the distribution constant, the fibre polymeric phase, and to the size of the molecular mass (e.g., polyunsaturated fatty acids and other compounds are expected to require longer extraction times depending on their lower partitioning and diffusion coefficient). In the present study, the results indicated that there were differences between all citrus fruit species by total peak area. Apparently, more 
volatiles are emitted in $2 \mathrm{~h}$ extraction time from orange fruit, and there were no significant differences in 2 and $4 \mathrm{~h}$ extraction time from lemon and mandarin, while total peak area from limes fruit reaches high level from $4 \mathrm{~h}$ extraction time (Figure 3), and this is because different species have different types and amounts of compounds. In general, all plants have the ability to emit VOCs, and the content and composition of these VOCs will depend on the plant species and plant organ.

There were significant differences between the three volumes of glass jars used to capture VOCs. However, since the $500 \mathrm{ml}$ glass jar proved to be the best in capturing the VOCs emitted from different citrus species, which agrees with the study by [32] who used a $2000 \mathrm{ml}$ glass jar to extract a number of high-quality VOCs from $1500 \mathrm{~g}$ of peach and pear fruit.

\section{Conclusion}

This study concluded that headspace solid-phase microextraction combined with gas chromatography and flame ionization detection can be used to detect $\mathrm{VOC} / \mathrm{s}$ from whole citrus fruit species without cutting or extracting juice and essential oil and the optimum condition for sealing and extraction time, were20, 16, 8 and 16 hours headspace equilibrium and 2, 4, 2 and 2 hours fiber exposure time for lemon, lime, mandarin, and orange respectively.

\section{Acknowledgements}

We thank the University of Mosul for a scholarship to the first author.

\section{References}

[1] Liu, Y.Q., Heying, E. and Tanumihardjo, S.A. (2012) History, Global Distribution, and Nutritional Importance of Citrus Fruits. Comprehensive Reviews in Food Science and Food Safety, 11, 530-545. https://doi.org/10.1111/j.1541-4337.2012.00201.x http://onlinelibrary.wiley.com/doi/10.1111/j.1541-4337.2012.00201.x/full

[2] Ladanyia, M. and Ladaniya, M. (2010) Citrus Fruit: Biology, Technology and Evaluation. Academic Press.

[3] Murray Darling Basin Authority (2010) Guide to the Proposed Basin Plan. MurrayDarling Basin Authority, Canberra.

https://www.citrusaustralia.com.au/wp-content/uploads/MDBA-Guide-to-proposed -Basin-Plan-submission-Dec10.pdf

[4] Manner, H.I., Buker, R.S., Smith, V.E., Ward, D. and Elevitch, C.R. (2006) Citrus (Citrus) and Fortunella (Kumquat). Species Profile for Pacific Island Agroforestry, 2, 1-35.

[5] Ortiz, J.M. (2002) Botany. In: Dugo, G. and Di Giacomo, A., Eds., Citrus. The Genus Citrus, Taylor and Francis, New York, 16-35.

[6] Tan, Q., Ai, M., and Minh, N. (2011) Volatile Constituents of Essential Oil from Citrus sinensis Grown in Tine Giant Province, Vietnam. Asian Journal of Food and Agro Industry, 4(, 183-186.

[7] Fares, S., Park, J.H., Gentner, D.R., Weber, R., Ormeño, E., Karlik, J. and Goldstein, A.H. (2012) Seasonal Cycles of Biogenic Volatile Organic Compound Fluxes and Concentrations in a California Citrus Orchard. Atmospheric Chemistry and Phys- 
ics, 12, 9865. https://doi.org/10.5194/acp-12-9865-2012

[8] Cavalli, J.F., Fernandez, X., Lizzani-Cuvelier, L. and Loiseau, A.M. (2003) Comparison of Static Headspace, Headspace Solid Phase Microextraction, Headspace Sorptive Extraction, and Direct Thermal Desorption Techniques on Chemical Composition of French Olive Oils. Journal of Agricultural and Food Chemistry, 51, 7709-7716. https://doi.org/10.1021/jf034834n

[9] González-Mas, M.C., García-Riaño, L.M., Alfaro, C., Rambla, J.L., Padilla, A.I. and Gutierrez, A. (2009) Headspace-Based Techniques to Identify the Principal Volatile Compounds in Red Grape Cultivars. International Journal of Food Science \& Technology, 44, 510-518. https://doi.org/10.1111/j.1365-2621.2008.01779.x http://onlinelibrary.wiley.com/doi/10.1111/j.1365-2621.2008.01779.x/full

[10] Jia, M., Zhang, Q.H. and Min, D.B. (1998) Optimization of Solid-Phase Microextraction Analysis for Headspace Flavor Compounds of Orange Juice. Journal of Agricultural and Food Chemistry, 46, 2744-2747. https://doi.org/10.1021/jf971020w

[11] Choi, H.S. and Min, K.C. (2004) Headspace-SPME Analysis of Citrus Hybrid, Hallabong. Food Science and Biotechnology, 13, 126-129.

[12] Atti-Santos, A.C., Rossato, M., Serafini, L.A., Cassel, E. and Moyna, P. (2005) Extraction of Essential Oils from Lime (Citrus latifolia Tanaka) by Hydrodistillation and Supercritical Carbon Dioxide. Brazilian Archives of Biology and Technology, 48, 155-160. https://doi.org/10.1590/S1516-89132005000100020

[13] Sikdar, D.C., Menon, R., Duseja, K., Kumar, P. and Swami, P. (2016) Extraction of Citrus Oil from Orange (Citrus sinensis) Peels by Steam Distillation and Its Characterizations. International Journal of Technical Research and Applications, 4, 341-346.

[14] Automatik, W. and Minyak, A.K.H. (2013) Extraction of Citrus hystrix DC (Kaffir Lime) Essential Oil Using Automated Steam Distillation Process: Analysis of Volatile Compounds. Malaysian Journal of Analytical Sciences, 17, 359-369.

[15] Sparinska, A. and Rostoks, N. (2015) Volatile Organic Compounds of Hybrid Rugosa Roses in Latvia. In Proceedings of the Latvian Academy of Sciences. Section B. Nat Exact Appl Sci., 69, 57-61.

[16] Najafian, S. and Rowshan, V. (2012) Comparative of HS-SPME and HD Techniques in Citrus aurantium L. Int JMed Arom Plants, 2, 488-494.

[17] Bicchi, C., Drigo, S. and Rubiolo, P. (2000) Influence of Fibre Coating in Headspace Solid-phase Microextraction Gas Chromatographic Analysis of Aromatic and Medicinal Plants. Journal of Chromatography A, 892, 469-485. https://doi.org/10.1016/S0021-9673(00)00231-4

[18] Dorea, H.S., Gaujac, A. and Navickien, S. (2008) Solid-Phase Microextraction: Thermodynamic and Kinetic Aspects. Scientia Plena, 4, 1-7.

[19] Jelen, H.H., Majcher, M. and Dziadas, M. (2012) Microextraction Techniques in the Analysis of Food Flavor Compounds: A Review. Analytica Chimica Acta, 738, 13-26. https://doi.org/10.1016/j.aca.2012.06.006

[20] Nongonierma, A., Cayot, P., Quere, J.L., Springett, M. and Voilley, A. (2006) Mechanisms of Extraction of Aroma Compounds From Foods, Using Adsorbents. Effect of Various Parameters. Food Reviews International, 22, 51-94. https://doi.org/10.1080/87559120500379951

[21] Chen, Z. X. and Lin, L. (2004) Study on Coumarin Compounds from Exocarpium Citri Grandis. Journal of Chinese Medicinal Materials, 27, 577-578.

[22] Bourgou, S., Rahali, F.Z., Ourghemmi, I. and Saïdani Tounsi, M. (2012) Changes of Peel Essential Oil Composition of Four Tunisian Citrus during Fruit Maturation. 
The Scientific World Journal. https://doi.org/10.1100/2012/528593

[23] Paliyath, G., Pessoa, F.L., Sidhu, J.S., Sinha, N. and Peggy Stanfield, R.D. (2010) Handbook of Fruit and Vegetable Flavors. In: Hui, Y.H., Chen, F. and Nollet, L.M., Eds., John Wiley and Sons.

[24] Sanz, C.A.R.L.O.S., Olias, J.M. and Perez, A.G. (1996) Aroma Biochemistry of Fruits and Vegetables. Proceedings-Phytochemical Society of Europe, 41, 125-156.

[25] Almenar, E., Del-Valle, V., Hernández-Muñoz, P., Lagarón, J.M., Catalá, R. and Gavara, R. (2007) Equilibrium Modified Atmosphere Packaging of Wild Strawberries. Journal of the Science of Food and Agriculture, 87, 1931-1939.

http://onlinelibrary.wiley.com/doi/10.1002/jsfa.2938/full https://doi.org/10.1002/jsfa.2938

[26] Both, V., Brackmann, A., Thewes, F.R., Ferreira, D.F. and Wagner, R. (2014) Effect of Storage under Extremely Low Oxygen on the Volatile Composition of "Royal Gala” Apples. Food Chemistry, 156, 50-57. https://doi.org/10.1016/j.foodchem.2014.01.094

[27] Barker, J. (1928) The Effect of Carbon Dioxide on Oranges. Gt. Brit. Dept. Sci. Ind. Research Rept. Food Invest. Board, 33.

[28] Shaw, P.E. (1991) Fruits II. In: Maarse, H., Ed., Volatile Compounds in Foods and Beverages, Marcel Dekker, New York, NY, USA, 305-327.

[29] Garruti, D.S., Cordenunsi, B.R. and Lajolo, F.M. (2013) Isolation of Volatiles Compounds in Banana by HS-SPME: Optimization for the Whole Fruit and Pulp. International Journal of Bioscience, Biochemistry and Bioinformatics, 3, 110.

[30] Zhang, C., Qi, M., Shao, Q., Zhou, S. and Fu, R. (2007) Analysis of the Volatile Compounds in Ligusticum chuanxiong Hort. Using HS-SPME-GC-MS. Journal of Pharmaceutical and Biomedical Analysis, 44, 464-470. https://doi.org/10.1016/j.jpba.2007.01.024

[31] Nardini, G.S., Merib, J.O., Dias, A.N., Dutra, J.N., Silveira, C.D., Budziak, D. and Carasek, E. (2013) Determination of Volatile Profile of Citrus Fruit by HS-SPME/GC-MS with Oxidized NiTi Fibers Using Two Temperatures in the Same Extraction Procedure. Microchemical Journal, 109, 128-133. https://doi.org/10.1016/j.microc.2012.03.024

[32] Lu, P.F., Qiao, H.L., Xu, Z.C., Cheng, J., Zong, S.X. and Luo, Y.Q. (2014) Comparative Analysis of Peach and Pear Fruit Volatiles Attractive to the Oriental Fruit Moth, Cydia molesta. Journal of Plant Interactions, 9, 388-395. https://doi.org/10.1080/17429145.2013.843724

Scientific Research Publishing

\section{Submit or recommend next manuscript to SCIRP and we will provide best service for you:}

Accepting pre-submission inquiries through Email, Facebook, LinkedIn, Twitter, etc. A wide selection of journals (inclusive of 9 subjects, more than 200 journals)

Providing 24-hour high-quality service

User-friendly online submission system

Fair and swift peer-review system

Efficient typesetting and proofreading procedure

Display of the result of downloads and visits, as well as the number of cited articles

Maximum dissemination of your research work

Submit your manuscript at: http://papersubmission.scirp.org/

Or contact jbm@scirp.org 